


\section{RUSSIAN ACADEMY OF SCIENCES \\ INSTITUTE FOR THE HISTORY OF MATERIAL CULTURE}

\section{B ULLETIN}

№ 10

RESCUE ARCHAEOLOGY

ST. PETERSBURG

2020 


\section{РОССИЙСКАЯ АКАДЕМИЯ НАУК \\ ИНСТИТУТ ИСТОРИИ МАТЕРИАЛЬНОЙ КУЛЬТУРЫ}

\section{БЮЛЛЕТЕНЬ}

№ 10

ОХРАННАЯ АРХЕОЛОГИЯ

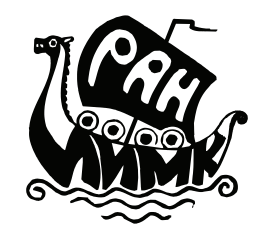

САНКТ-ПЕТЕРБУРГ

2020 
УДК 902/904

ББК 63.4

Б98

Рецензенты:

В.А. Лапшин (директор ИИМК РАН)

И. Л. Тихонов (Институт истории СПбГУ)

Ответственный редактор Н.Ф. Соловьёва

Технический редактор, оформитель С. Л. Соловьёв

Перевод: А.В. Гилевич

Корректор: А.О. Поликарпова

Бюллетень Института истории материальной культуры Российской академии наук: (охранная археология). [№] 10 / науч. ред. Н.Ф. Соловьёва;

ИИМК РАН. - СПб.: Изд-во ООО «Невская Типография», 2020. - 193 с. : ил.

Bulletin of the Institute for the History of Material Culture Russian Academy of Sciences:

(rescue archaeology). [№] 10 / ed. by N.F. Solovyova;

IHMC RAS. - SPb.: Publishing House LLC «Nevsky Printing House», 2020. - 193 pp. : ill.

ISBN 978-5-907298-13-2

Периодическое издание посвящено охранно-археологической деятельности ИИМК РАН по изучению культурного наследия России. Десятый номер бюллетеня представляет результаты археологических исследований объектов культурного наследия Санкт-Петербурга и его окрестностей, а также других регионов России, которые были осуществлены Отделом охранной археологии ИИМК РАН в сотрудничестве с другими научными, образовательными и государственными организациями в 2017-2020 гг.

Издание предназначено для историков, археологов, государственных служащих, частных предпринимателей и широкого круга читателей, заинтересованных в научной и достоверной информации об истории России и состоянии памятников ее культуры.

This periodical is dedicated to the rescuing and archaeological activities of the Institute for the History of Material Culture (IHMC) RAS in studies of the cultural heritage of Russia. The tenth issue of the Bulletin presents the results of archaeological investigations of the cultural heritage of St. Petersburg and its surroundings, as well as other regions of Russian Federation, carried out in 2017-2020 by the Department for Rescue Archaeology of IHMC RAS in collaboration with other scientific, educational and public organizations.

This publication is intended for historians, archaeologists, government employees, private entrepreneurs and a wide circle of readers interested in reliable scientific information on history of Russia and the state of the monuments of its culture.

ISBN 978-5-907298-13-2

УДК 902/904

ББК 63.4

(С) ИИМК РАН, Санкт-Петербург, 2020

(c) Отдел охранной археологии ИИМК РАН, 2020 


\title{
О манипуляциях с умершими в могильнике Смирновка-4 (предварительное сообщение) ${ }^{1}$
}

\author{
Н.И. Лазаретова ${ }^{2}$
}

DOI: $10.31600 / 978-5-907298-13-2-2020-189-191$

В результате спасательных археологических раскопок восьми курганов скифской эпохи на могильнике Смирновка-4 в 2020 г. были получены значительные антропологические материалы. Работы проводились Южносибирским филиалом ИИМК РАН на территории Восточно-Бейского угольного разреза, расположенного в Бейском районе республики Хакасия.

По существующей периодизации основные комплексы памятника относятся к биджинскому и сарагашенскому этапам тагарской культуры (Грязнов и др., 1979. С. 3-6) и содержат 15 коллективных захоронений скифского времени. Как выяснилось в ходе раскопок, данные курганы были устроены поверх уже существовавших оград эпохи поздней бронзы, от которых сохранились отдельные элементы каменных конструкций, несколько грунтовых могил, преимущественно детских, и немногочисленные артефакты. В гунно-сарматское время в насыпи скифских курганов было впущено свыше 220 объектов тесинской археологической культуры: захоронения взрослых и детей в грунтовых ямах, разнообразных каменных и деревянных конструкциях; парциальные погребения, содержавшие отдельные части человеческих скелетов (часть грудной клетки, коленные чашечки, фрагменты тазовых костей), срезанные вместе с мягкими тканями; кенотафы; ритуальные ямы с отдельными сосудами и костями животных. Многие из них оказались частично разрушены или перемещены в ходе позднейших перекопов и ограблений. Большая плотность разновременных захоронений, обилие деревянных конструкций и бересты отрицательно

\footnotetext{
1 Работа выполнена в рамках программы ФНИ ГАН по теме государственного задания № 0160-2019-0044 «Разработка научных подходов, систематизации, научного описания, реставрации, консервации и хранения археологических коллекций».

2 Россия, 191186, Санкт-Петербург, Дворцовая наб., 18. Институт истории материальной культуры РАН. E-mail: natasha-lazaretova@yandex.ru.
}

сказались на сохранности костного материала. Учет точного количества погребенных, определение их половозрастных данных возможны далеко не во всех случаях.

Гунно-сарматский период в истории Хакасии интересен одновременным существованием двух, совершенно разных погребальных традиций: коллективные захоронения в курганах-склепах (до 200 покойников) и грунтовые могильники, зачастую впущенные в насыпи курганов предшествующих эпох. По состоянию на 2011 г. было исследовано 33 больших кургана-склепа, один малый курган-склеп, а также 880 грунтовых могил (Кузьмин, 2011. С. 26). Характерной особенностью погребального обряда для курганов-склепов является массовая посмертная трепанация черепов, в отдельных случаях зафиксировано изготовление на основе человеческого скелета кукол-манекенов, обтянутых кожей, чаще - обмотка костей жгутами травы, берестой. Для грунтовых могильников подобный обряд не характерен и встречается лишь в единичных случаях. Так, в грунтовых могильниках Каменка III и Каменка V, раскопанных Я.А. Шером в 1964-1967 гг., были обнаружены несколько обмазанных глиной и гипсом трепанированных черепа (Шер, Хлобыстин, 1966. С. 10-12; Шер и др., 1967. С. $145-147 ; 1968$. С. 150, 151). Такие «глиняные головы» относятся Э.В. Вадецкой, как правило, к позднетесинским куклам и датируются III-IV вв. (Вадецкая, 2018. С. 169). Наличие раскрашенных масок также хронологически приближает их к таштыкскому времени.

В могильнике Смирновка-4 посмертные манипуляции путем удаления кусочка черепной крышки отмечены у четырех погребенных: один - из кургана 3, три - из кургана 5 (рис. 1-4). Все трепанированные черепа из кургана 5 женские (рис. 2-4). Локализация отверстий отмечается слева в височнотеменной области и справа в височно-теменной и теменной (чуть затронут край затылочной кости) областях. Как ранее уже отмечалось, лобную кость 


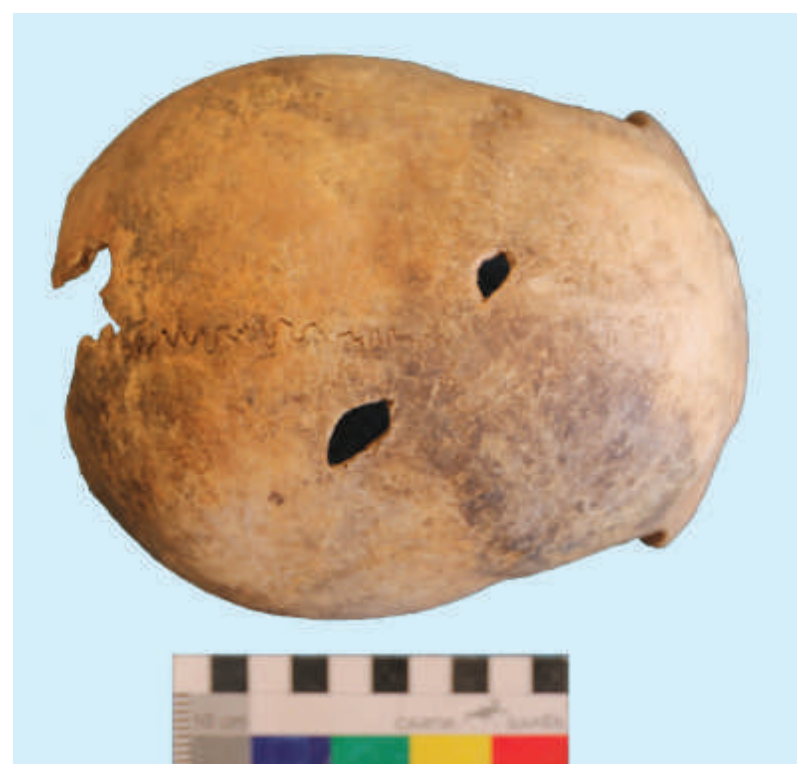

Рис. 1. Смирновка-4, курган 3, объект 21. Череп с затылочной трепанацией и повреждениями от чеканов

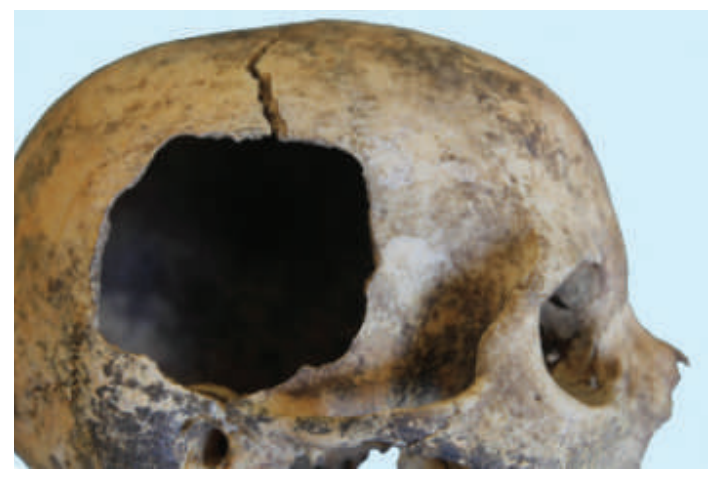

Рис. 2. Смирновка-4, курган 5, объект 10. Височнотеменная трепанация на черепе справа

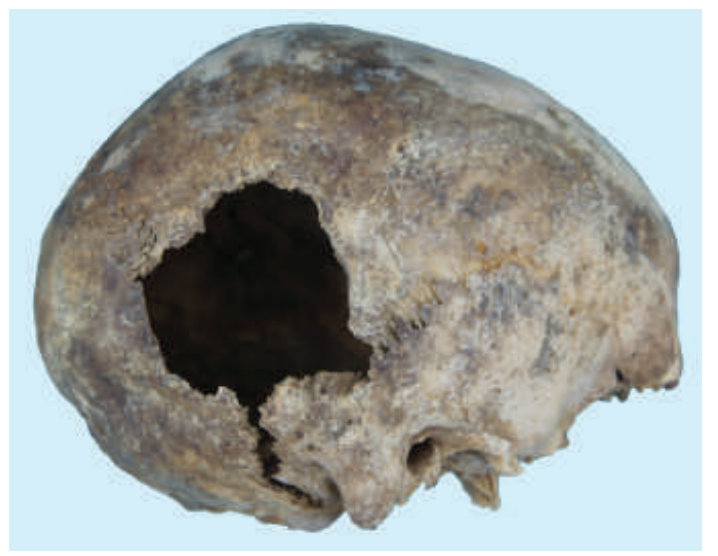

Рис. 3. Смирновка-4, курган 5, череп из насыпи 1. Теменная трепанация на черепе справа

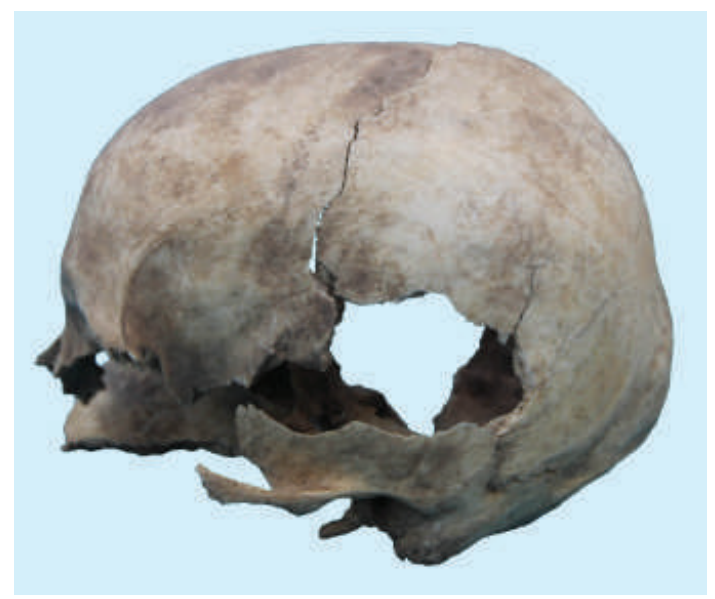

Рис. 4. Смирновка-4, курган 5, череп из насыпи 2. Височно-теменная трепанация на черепе слева

обычно не резали (Гиря и др., 2020. С. 144-147). Череп из кургана 3 трепанирован в затылочной части и принадлежит мужчине в возрасте около 25 лет (рис. 1). Кроме того, череп данного индивида оказался пробит в трех местах (лобная кость, правая и левая теменная) разными орудиями, по-видимому, чеканами, имевшими овальные и круглые в сечении бойки. Еще один череп, поврежденный чеканом и, вероятно, плоским топориком, обнаружен в данном могильнике в заполнении могилы 1 кургана 2. Здесь наблюдаются три круглых отверстия от чекана на лобной кости и чуть выше с захватом правой теменной пробоина от топорика. Этот скелет датируется сарагашенским временем. Подобные черепа с повреждениями встречаются в курганах разных эпох на территории Хакасско-Минусинских котловин.

У погребенного в объекте 27 кургана 8 сохранность костного материала не позволила зафиксировать наличие трепанации на черепе (рис. 5). Однако череп, набитый травой, отдельные кости, обернутые берестой, являются, видимо, берестяной куклой, ее создавали путем обматывания всего костяка жгутами из трав и обшивания берестой (Вадецкая, Поселянин, 2011. С. 13-18; Вадецкая, 2018. С. 167; 168). Такие куклы-мумии названы Э.Б. Вадецкой белоярскими и отнесены к самым ранним (Вадецкая, 2018. С. 167). Вероятно, в объекте 27 кургана 8 на дне могилы рядом лежали две таких куклы-мумии. От второго скелета сохранились только единичные кости и тлен. Несомненно, данные манипуляции с телами умерших могильника Смирновка-4 хронологически более ранние, нежели операции с телами из археологических памятников Каменка III и Каменка V, описанные в публикациях. 


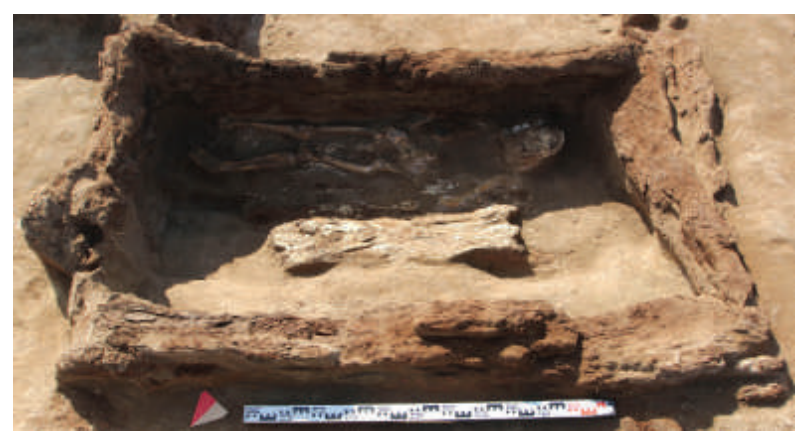

Рис. 5. Смирновка-4, курган 8, объект 27. Погребение кукль-мумии

Характерная для склепов традиция мумификации тел умерших в могильнике Смирновка-4 свидетельствует о взаимодействии двух групп тесинской культуры, совершавших захоронения в курганахсклепах и грунтовых могильниках по разным обрядам. Возможно, в дальнейшем при работе с антропологическими материалами других грунтовых памятников тесинского времени будут найдены дополнительные подтверждения этого, что позволит увереннее говорить о единстве культуры и взаимных контактах групп населения Присаянья, хоронивших своих усопших по таким разным обрядам.

\section{Источники и литература}

Вадецкая Э. Б., 2018. Отражение в коллективных могилах Енисея представлений о смерти индивида и возрождении социума // Древние некрополи погребально-поминальная обрядность, погребальная архитектура и планировка некрополей. СПб.

Вадецкая Э. Б., Поселянин А. И., 2011. Реконструкции кукол-мумий из кургана Белый Яр VI под Абаканом // Научное обозрение Саяно-Алтая. Абакан. № 1.

Гиря Е. Ю., Учанева Е. Н., Малютина А. А., Бусова В. С., Лазаретова Н. И., 2020. Трасологическое исследование следов трепанации на черепах из могильников Белый Яр VI, Степновка II, Большое Русло (тесинский этап тагарской культуры) // Первобытная археология. Журнал междисциплинарных исследований. СПб. № 1.

Грязнов М. П., Завитухина М. П., Комарова М. Н., Миняев С. С., Пшеницына М. Н., Худяков Ю. С., 1979. Комплекс археологических памятников у горы Тепсей на Енисее. Новосибирск.
Кузьмин Н. Ю., 2011. Погребальные памятники хунно-сяньбийского времени в степях Среднего Енисея: Тесинская культура. СПб.

Шер Я. А., Хлобыстин Л. П., 1966. Раскопки на среднем Енисее // АО 1965 года.

Шер Я. А., Григорьев Г. П., Подольский Н. Л., 1967. Находки на правобережье Енисея // АО 1966 года.

Шер Я. А., Савинов Д. Г., Подольский М. Л., Кляшторный С. Г., 1968. Курганы и писаницы правобережья Енисея // АО 1967 года. 